\title{
Correction to: Effect of action-based cognitive remediation on cognition and neural activity in bipolar disorder: study protocol for a randomized controlled trial
}

Caroline V. Ott ${ }^{1,2}$, Maj Vinberg ${ }^{1}$, Christopher R. Bowie ${ }^{3}$, Ellen Margrethe Christensen', Gitte M. Knudsen ${ }^{4,5}$, Lars V. Kessing ${ }^{1,5}$ and Kamilla W. Miskowiak ${ }^{1,2^{*}}$

Correction to: Trials (2018) 19:487

https://doi.org/10.1186/s13063-018-2860-8

Following publication of the original article [1], the authors notified us that a comment in the Peripheral and neural biomarkers and genotype section was incorrectly phrased during editing. " 4 weeks of treatment (four active ABCR sessions twice a week or control group sessions twice a week)" should have actually been described as "two weeks of treatment (4 active, twice a week, ABCR sessions or 2 weekly control group sessions)".

\footnotetext{
Author details

${ }^{1}$ Copenhagen Affective Disorder Research Center (CADIC), Psychiatric Centre Copenhagen, Copenhagen University Hospital, Rigshospitalet, Copenhagen,

Denmark. ${ }^{2}$ Department of Psychology, University of Copenhagen, Copenhagen, Denmark. ${ }^{3}$ Psychology Department, Queen's University, Kingston, ON, Canada. ${ }^{4}$ Neurobiology Research Unit and Center for Experimental Medicine Neuropharmacology, Rigshospitalet, Copenhagen, Denmark. ${ }^{5}$ Faculty of Health and Medical Sciences, University of

Copenhagen, Copenhagen, Denmark.
}

Received: 13 March 2019 Accepted: 13 March 2019

Published online: 08 April 2019

\section{Reference}

1. Ott CV, et al. Effect of action-based cognitive remediation on cognition and neural activity in bipolar disorder: study protocol for a randomized controlled trial. Trials. 2018;19:487. https://doi.org/10.1186/s13063-018-2860-8.

\footnotetext{
* Correspondence: kamilla.woznica.miskowiak@regionh.dk

${ }^{1}$ Copenhagen Affective Disorder Research Center (CADIC), Psychiatric Centre Copenhagen, Copenhagen University Hospital, Rigshospitalet, Copenhagen, Denmark

2Department of Psychology, University of Copenhagen, Copenhagen,

Denmark

Full list of author information is available at the end of the article
}

(c) The Author(s). 2019 Open Access This article is distributed under the terms of the Creative Commons Attribution 4.0 International License (http://creativecommons.org/licenses/by/4.0/), which permits unrestricted use, distribution, and reproduction in any medium, provided you give appropriate credit to the original author(s) and the source, provide a link to the Creative Commons license, and indicate if changes were made. The Creative Commons Public Domain Dedication waiver (http://creativecommons.org/publicdomain/zero/1.0/) applies to the data made available in this article, unless otherwise stated. 